\title{
Maintenance of influenza virus infectivity on the surfaces of personal protective equipment and clothing used in healthcare settings
}

\author{
Hiroko Sakaguchi $\cdot$ Koji Wada $\cdot$ Jitsuo Kajioka \\ Mayumi Watanabe • Ryuichi Nakano - Tatsuko Hirose • \\ Hiroshi Ohta $\cdot$ Yoshiharu Aizawa
}

Received: 20 December 2009/Accepted: 15 April 2010/Published online: 12 May 2010

(C) The Japanese Society for Hygiene 2010

\begin{abstract}
Objectives The maintenance of infectivity of influenza viruses on the surfaces of personal protective equipment and clothing is an important factor in terms of controlling viral cross-infection in the environment and preventing contact infection. The aim of this study was to determine if laboratory-grown influenza A (H1N1) virus maintained infectivity on the surfaces of personal protective equipment and clothing used in healthcare settings.

Methods Influenza A virus $(0.5 \mathrm{~mL})$ was deposited on the surface of a rubber glove, an N95 particulate respirator, a surgical mask made of non-woven fabric, a gown made of Dupont Tyvek, a coated wooden desk, and stainless steel. Each sample was left for 1,8 , and $24 \mathrm{~h}$, and hemagglutination (HA) and 50\% tissue culture infective dose $\left(\mathrm{TCID}_{50}\right) / \mathrm{mL}$ were measured.

Results The HA titer of this influenza A virus did not decrease in any of the materials tested even after $24 \mathrm{~h}$. The infectivity of influenza A virus measured by $\mathrm{TCID}_{50}$ was
\end{abstract}

\section{H. Sakaguchi}

Department of Occupational Health,

Graduate School of Medical Sciences,

Kitasato University, Tokyo, Japan

K. Wada $(\bowtie) \cdot$ H. Ohta $\cdot$ Y. Aizawa

Department of Preventive Medicine and Public Health,

Kitasato University School of Medicine, 1-15-1 Kitasato,

Sagamihara, Kanagawa 228-8555, Japan

e-mail: kwada-sgy@umin.ac.jp

J. Kajioka $\cdot$ M. Watanabe $\cdot$ R. Nakano

Kitasato Research Center of Environmental Sciences,

Sagamihara, Kanagawa 228-8555, Japan

\section{T. Hirose}

School of Allied Health Sciences, Kitasato University,

Sagamihara, Kanagawa 228-8555, Japan maintained for $8 \mathrm{~h}$ on the surface of all materials, with the exception of the rubber glove for which virus infectivity was maintained for $24 \mathrm{~h}$.

Conclusions Our results indicate that the replacement/ renewal of personal protective equipment and clothing by healthcare professionals in cases of exposure to secretions and droplets containing viruses spread by patients is an appropriate procedure to prevent cross-infection.

Keywords Control - Cross-infection · Environment . Infectivity $\cdot$ Influenza

\section{Introduction}

Healthcare professionals may be exposed to high doses of influenza viruses during their examination of patients [1]. The healthcare environment is commonly contaminated with secretions and droplets, including viruses spread by patients. It is likely that viruses shed by influenza virusinfected patients are responsible for the maintenance of virus infectivity in the environment [2-5]. Accordingly, measures should be taken to limit influenza virus contamination of the environment to prevent cross-infection among healthcare professionals.

Healthcare professionals use personal protective equipment and clothing to prevent infection [6,7] that may include any type of clothing, equipment, or respiratory protective device designed to protect against droplet infection [8]. Personal protective equipment and clothing, such as gloves, gowns, surgical masks, and N95 particulate respirators, can prevent direct contact with viruses, but the surface of the equipment may still become contaminated [9-11] with virus particles. Consequently, the inappropriate disposal of such protective equipment and clothing after 
use may result in inadvertent exposure to virus contamination through contact with the surface of the material. Additionally, people frequently touch their face with their hands [12], which may also result in contact infection.

A number of studies have shown that the influenza virus can maintain infectivity on environmental surfaces. Bean et al. [13] investigated the survival of laboratory-grown influenza A (H1N1) virus on the surfaces of various materials, such as stainless steel, plastic, pajamas, tissue paper, magazines, and a handkerchief. These researchers found that the $50 \%$ of the tissue culture infective dose $\left(\mathrm{TCID}_{50}\right)$ was reduced to below the detection limit on the pajamas, tissue paper, magazines, and a handkerchief after $12 \mathrm{~h}$, while the virus maintained infectivity for $24 \mathrm{~h}$ on the plastic and stainless steel surfaces, with the TCID $_{50}$ falling below the detection limit only after $48 \mathrm{~h}$.

In order to prevent cross-infection via personal protective equipment in healthcare settings, it is necessary to know how long the influenza virus maintains infectivity on the surface of such equipment. However, to the best of our knowledge, there have been very few studies on this aspect of virus infectivity and public healthcare. The aim of this study was to determine both whether influenza viruses maintain infectivity and survive on the surfaces of personal protective equipment in healthcare settings and the appropriate time to replace personal protective equipment.

\section{Materials and methods}

In this study we used influenza A (H1N1) virus strain A/ PR/8/34 [ATCC VR-95, 1280 hemagglutination (HA) units, 1999-12-10] obtained from allantoic fluid. We conducted a series of experiments designed to assess the duration of the infectivity of influenza A viruses on the surfaces of personal protective equipment in healthcare settings.

The surfaces used as test materials included a rubber glove, an N95 particulate respirator (Hi-Luck 350; Koken, Tokyo, Japan), a surgical mask made of non-woven fabric, a gown made of Dupont Tyvek, a coated wooden desk, and stainless steel. Tyvek is a material made from 0.5- to 10$\mu \mathrm{m}$, very fine, continuous polyethylene fibers bonded together by heat. Being very soft and strong, it is widely used as a material for gowns used by healthcare professionals [14]. A coated wooden desk and stainless steel surface were used as samples for comparison with personal protective equipment. A sample $(0.5 \mathrm{~mL})$ of viral suspension containing $10^{3.8} \mathrm{TCID}_{50} / \mathrm{mL}$ was deposited on a $3-\mathrm{cm}^{2}$ area of each test material. A $0.5-\mathrm{mL}$ volume was selected because this volume was the optimal volume for collection with a cotton pad.
The HA and the $\mathrm{TCID}_{50} / \mathrm{mL}$ were measured at $0 \mathrm{~h}$, immediately after application of the viral suspension, to provide baseline data to monitor the changes over time. Aliquots of influenza A/PR/8/34(H1N1) were deposited and remained on the surface of each material for $0,1,8$, or $24 \mathrm{~h}$. The temperature of the laboratory was maintained at $25.2^{\circ} \mathrm{C}$, and the relative humidity was $55 \%$.

At the specified time periods post-virus application $(1,8$, $24 \mathrm{~h}$ ), a piece of the rubber glove, N95 particulate respirator, surgical mask made of a non-woven fabric, and gown made of Dupont Tyvek were each placed in a separate centrifuge tube containing $5 \mathrm{~mL}$ phosphate-buffered saline (PBS). If liquid was left on the coated wooden desk or stainless steel, it was aspirated with a dropper, and the residual liquid was wiped with absorbent cotton. Both the aspirated liquid and the absorbent cotton were also placed in a centrifuge tube containing $5 \mathrm{~mL}$ PBS. The solution containing the recovered virus from each material was then mixed for $30 \mathrm{~s}$ on a vortex mixer to dislodge any attached test virus. The virus solutions obtained were used for quantification. Figure 1 shows the procedure for recovering the virus on the coated wooden desk and stainless steel surfaces.

\section{Determination of HA titer}

The recovered virus solution $(50 \mu \mathrm{L})$ was serially diluted twice with $50 \mu \mathrm{L}$ veronal-buffered saline (diluent), $\mathrm{pH}$ 6.6, and $50 \mu \mathrm{L}$ of $1 \%$ avian erythrocyte solution prepared using the diluent was then added and mixed. The mixture was allowed to stand in a refrigerator before the HA titer was defined as the highest dilution causing agglutination.

\section{Determination of virus infectivity titer $\left(\mathrm{TCID}_{50}\right)$}

Virus preparations recovered from various surfaces were serially diluted tenfold in PBS. The diluted virus solutions were used to inoculate Madin-Darby canine kidney (MDCK) cells cultured in medium [Dulbecco's modified Eagle's medium supplemented with 5\% fetal bovine serum (FBS) and containing $100 \mathrm{IU} / \mathrm{mL}$ penicillin and $100 \mathrm{mg} / \mathrm{mL}$ streptomycin) in 96-well plates and incubated for 3 days in a $5 \% \mathrm{CO}_{2}$ incubator at $37^{\circ} \mathrm{C}$. After incubation, the cells in each well were examined by light microscopy to observe any cytopathic effect (CPE) caused by virus infection. The $\mathrm{TCID}_{50}$ was determined as the dilution of sample at which the virus infected $50 \%$ of the MDCK cells in the wells to cause CPE. Since the influenza virus is able to infect MDCK cells, the appearance of CPE was considered to be specifically caused by influenza virus infection. The appearance of normal MDCK cells is shown in Fig. 2a, while cells showing typical CPE due to virus proliferation are shown in Fig. $2 \mathrm{~b}$. The $\mathrm{TCID}_{50}$ was 

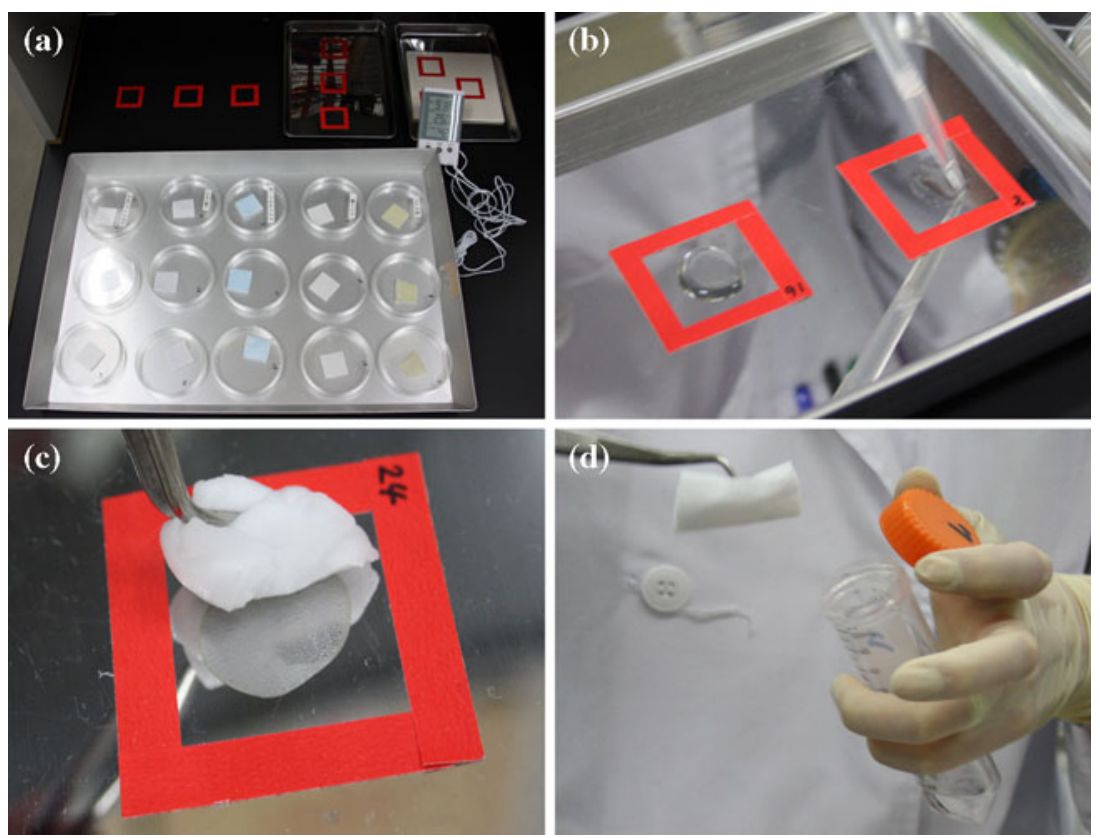

Fig. 1 Methods used for virus inoculation and subsequent virus isolation from various surfaces. a Virus was recovered from a $3-\mathrm{cm}^{2}$ test piece of a rubber glove, N95 particulate respirator, non-woven surgical mask, and gown made of Dupont Tyvek. A $3-\mathrm{cm}^{2}$ area of coated wooden desk and stainless steel was enclosed with tape for application of the viral suspension. b The liquid remaining on the coated wooden desk and stainless steel was recovered by aspiration

with a dropper. $\mathbf{c}$ The residual liquid after aspiration and the dried liquid were recovered by wiping with absorbent cotton. $\mathbf{d}$ The liquid thus recovered was placed in a centrifuge tube containing $5 \mathrm{~mL}$ phosphate buffered saline, and the resulting solution was mixed for $30 \mathrm{~s}$ on a Vortex mixer to wash out the test virus. The virus solutions thus obtained were used as samples for quantification

Fig. 2 Cytopathic effect (CPE) observed in influenza virusinoculated Madin-Darby canine kidney (MDCK) cells. a Normal, uninfected MDCK cells, b MDCK cells showing cell rounding consistent with the CPE observed with influenza virus proliferation
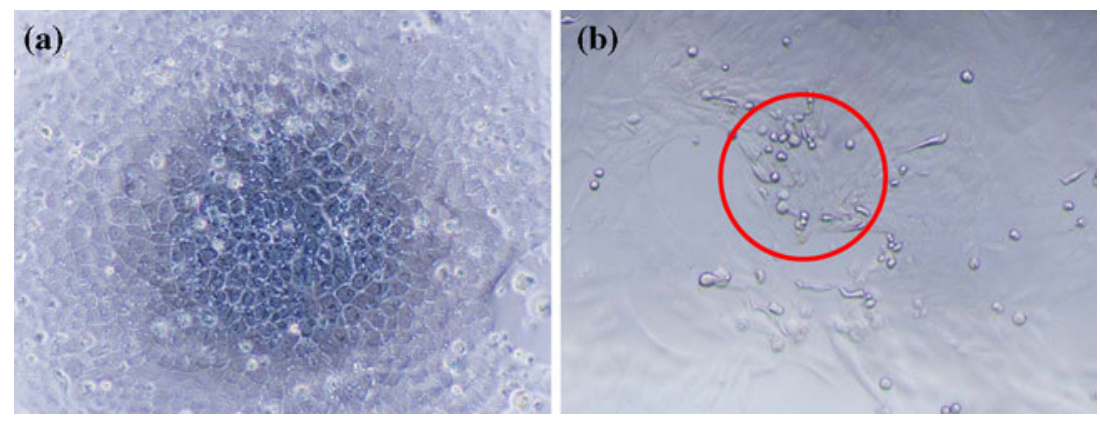

determined on the basis of the number of CPE-positive wells to calculate the infectivity titer of the test virus $\left(\mathrm{TCID}_{50} / \mathrm{mL}\right)$ and calculated using the Reed-Muench formula [15].

\section{Results}

The HA titer of the influenza virus solution was determined to be 64 for all samples at $0 \mathrm{~h}$, immediately after the application of virus suspensions onto the surface of each material. At 1, 8, and $24 \mathrm{~h}$ post-virus application, the HA titer on the surface of all samples was 32, demonstrating that the HA titer of the influenza virus remained stable over time without any marked decrease, irrespective of the material.
The $\mathrm{TCID}_{50} / \mathrm{mL}$ of the solution of influenza virus was $10^{3.8}$ for all samples of the virus recovered at $0 \mathrm{~h}$, immediately after application of the virus suspension. At 1,8 , and $24 \mathrm{~h}$ post-virus application, the $\mathrm{TCID}_{50} / \mathrm{mL}$ of the virus suspension on the surface of the rubber glove was $10^{2.8}$. In comparison, the $\mathrm{TCID}_{50} / \mathrm{mL}$ of the virus suspension on the N95 particulate respirator surface was $10^{3.0}$ after $1 \mathrm{~h}$, increasing to $10^{3.8}$ after $8 \mathrm{~h}$, before decreasing to $10^{0.8}$ after $24 \mathrm{~h}$. Similar to the N95 particulate respirator surface, the mask made of a non-woven fabric had a $\mathrm{TCID}_{50} / \mathrm{mL}$ of $10^{0.8}$ after $24 \mathrm{~h}$. Virus survival on the Tyvek surface was determined to be $10^{2.8} \mathrm{TCID}_{50} / \mathrm{mL}$ after $8 \mathrm{~h}$ and $10^{0.8}$ after $24 \mathrm{~h}$. On the surface of the coated desk, the TCID $50 / \mathrm{mL}$ was $10^{3.6}$ after $1 \mathrm{~h}, 10^{2.8}$ after $8 \mathrm{~h}$, and $10^{0.8}$ after $24 \mathrm{~h}$. The $\mathrm{TCID}_{50} / \mathrm{mL}$ on the stainless steel surface was $10^{2.8}$ after 


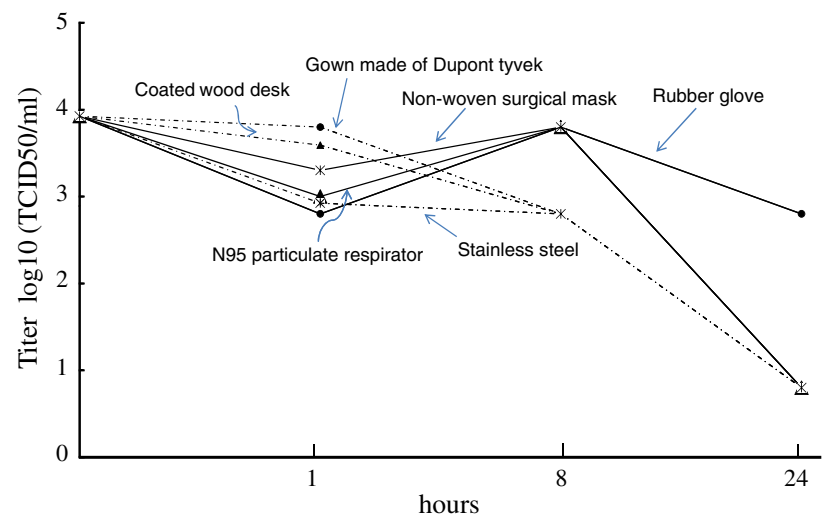

Fig. 3 The value of $50 \%$ tissue culture infective dose $\left(T C I D_{50}\right)$ of influenza virus recovered from various surfaces after $0,1,8$, and $24 \mathrm{~h}$ exposure. The detection limit of the $\mathrm{TCID}_{50}$ assay was determined to be $0.8 \log _{10} \mathrm{TCID}_{50} / \mathrm{mL}$

$8 \mathrm{~h}$ and $10^{0.8}$ after $24 \mathrm{~h}$. Figure 3 shows a summary of the changes in $\mathrm{TCID}_{50} / \mathrm{mL}$ for the influenza virus suspension allowed to stand on the surface of each material for the specified periods.

\section{Discussion}

The aim of this study was to assess the time course of changes in influenza virus infectivity on personal protective equipment used in healthcare settings. The results demonstrate that the virus TCID $_{50}$ was relatively stable at a certain level on the surface of personal protective equipment after $8 \mathrm{~h}$. However, after $24 \mathrm{~h}$, while the HA titer remained at a relatively stable level in all samples, the TCID $_{50}$ decreased to below the detection limit in all samples except the rubber glove.

The stability of the HA titer after $24 \mathrm{~h}$ seems to be explained by the inherent properties of virus-associated carbohydrates and proteins. Hemagglutinin, found on the surface of the influenza virus, is composed of sialic acidbinding polysaccharides [16] and carbohydrates resistant to heat and dryness. Since the HA assay detects the red blood cell agglutinating ability of hemagglutinin, regardless of the presence of infectious influenza virus, the assay was able to detect HA even after $24 \mathrm{~h}$. In contrast, virus-associated proteins necessary for the infectivity of influenza virus are susceptible to heat and dryness, and this susceptibility is likely to be the reason why the virus infectivity, as determined by $\mathrm{TCID}_{50}$, was reduced over time.

Surgical masks and N95 particulate respirators are made from non-woven fabric and are used by healthcare professionals during patient examinations [9, 17, 18] or by patients to prevent transmission of a virus [19, 20]. In our experiments, the virus maintained infectivity on the surfaces of the surgical mask and the N95 particulate respirator for at least $8 \mathrm{~h}$. There have been no reports to date on the maintenance of infectivity of the influenza virus on non-woven fabric surface. However, Bean et al. [13] reported that the $\mathrm{TCID}_{50}$ on the surface of a handkerchief and pajamas decreased to below the detection limit in $12 \mathrm{~h}$.

We considered that a virus would dry on the Tyvek surface, a material used to manufacture medical gowns because these materials do not absorb water. We observed that under our experimental conditions, the virus maintained its infectivity for at least $8 \mathrm{~h}$, but it was below the detection limit after $24 \mathrm{~h}$.

In our study, a coated wooden desk and stainless steel were used as samples for comparison with personal protective equipment. In healthcare settings, these materials may be contaminated by droplets containing pathogens from patients [11]. These materials, as well as Tyvek, do not absorb water. We found that the influenza virus maintained infectivity for at least $8 \mathrm{~h}$ post-virus application on the surface of these materials, without showing any decrease in $\mathrm{TCID}_{50}$, subsequently falling to below the detection limit in $24 \mathrm{~h}$. This finding suggests that the virus did not maintain its infectivity for $24 \mathrm{~h}$, which is consistent with the results obtained from the samples of personal protective equipment. According to Bean et al. [13], a laboratory-grown influenza A virus (A/H1N1) maintained infectivity for at least $24 \mathrm{~h}$ on the surface of stainless steel at a temperature between 27.8 and $28.3^{\circ} \mathrm{C}$ and $35-40 \%$ relative humidity, and $\mathrm{TCID}_{50}$ reached the detection limit in $48 \mathrm{~h}$. During our study, the temperature of the laboratory was maintained at $25.2^{\circ} \mathrm{C}$ and $55 \%$ relative humidity. This humidity was slightly higher than that in the study conducted by Bean et al. [13] and was less favorable for infectivity of the influenza virus [21, 22].

Rubber gloves are recommended as a standard public health precaution [23, 24] and are used for almost all procedures in healthcare settings [25]. Under the conditions of this study, the $\mathrm{TCID}_{50}$ on the surface of the rubber glove remained at a relatively stable level for at least $24 \mathrm{~h}$ postvirus application. Future studies should focus on whether a virus maintains its infectivity for more than $24 \mathrm{~h}$ on the surface of rubber gloves under the same conditions. One possible mechanism for the infectivity of the virus being maintained on the rubber glove is that the surface of the rubber glove was hydrophobically treated, while the other samples were hydrophilic. The virus solution formed water droplets on the rubber glove and, as a result, the droplets became embedded in the protein of the egg used to proliferate the laboratory-grown influenza virus, consequently protecting the virus from drying out.

It is clear from the results of our studies that influenza virus contained in droplets is able to maintain its infectivity on the surface of personal protective equipment as well as on a coated wooden desk and stainless steel in medical 
settings for at least $8 \mathrm{~h}$. However, on the surface of rubber gloves, the virus can maintain its infectivity for the relatively long time of $24 \mathrm{~h}$. Accordingly, healthcare professionals should renew/replace personal protective equipment if they have been exposed to droplets from patients with influenza [26, 27]; however, in practice, personal protective equipment cannot be replaced for each patient. For example, during the severe acute respiratory syndrome (SARS) panademic, personal protective equipment could not be replaced for each patient for the simple reason that there was a shortage in the supply of such equipment and clothing [28]. However, our findings suggest that caring for patients without an renewal or replacement of protective equipment may be responsible for cross-infection of influenza virus and, therefore, that a frequent replacement of personal protective equipment for each patient would prevent cross-infection. Since we have shown that the influenza virus maintains infectivity for at least $8 \mathrm{~h}$ on almost all surfaces, the disposal of personal protective equipment to prevent cross-infection after possible exposure to influenza virus is an important healthcare procedure.

This study has a number of limitations. First, the experiments were only conducted at one specific temperature and 55\% relative humidity. This experiment should be conducted under various conditions of low temperatures and low humidity, such as those found during winter when an influenza pandemic is likely to break out. The second limitation is that our experiments did not assess the time course of changes in virus infectivity between 8 and $24 \mathrm{~h}$. Therefore, the possibility cannot be ruled out that infectivity was lost in $<24 \mathrm{~h}$. The third limitation is that our experiments used a laboratorygrown influenza A virus, while a previous study conducted to assess the infectivity of the influenza virus showed that influenza virus mixed with human mucus maintained its infectivity on the surfaces of banknotes up to 17 days [29]. On the basis of this latter finding, we hope to investigate the infectivity of dried influenza virus or droplets mixed with mucus on the surfaces of personal protective equipment. Since the amount of virus in droplets emitted from patients with influenza has not been reported in the literature, it is unknown whether the amount of virus in such droplets is equivalent to that in the virus solution used in our experiments. This issue remains to be elucidated in future studies. Further studies involving a larger number of samples are required to assess the validity of this study.

In conclusion, the appropriate exchange of personal protective equipment in cases of exposure to secretions and droplets, including viruses spread by patients, should be encouraged among healthcare professionals to prevent cross-infection of the influenza virus.
Acknowledgments We thank Tomomi Yoshida of Kitasato University School of Allied Health Sciences for her editorial assistance and all of the people who cooperated in the study. This study was supported by the Kitasato Research Center of Environmental Sciences.

\section{References}

1. Swaminathan A, Martin R, Gamon S, Aboltins C, Athan E, Braitberg $\mathrm{G}$, et al. Personal protective equipment and antiviral drug use during hospitalization for suspected avian or pandemic influenza. Emerg Infect Dis. 2007;13:1541-7.

2. West K. Infection-control basics. A common sense review for EMS personnel. J Emerg Med Serv. 2002;27:115-25.

3. Barker J, Stevens D, Bloomfield SF. Spread and prevention of some common viral infections in community facilities and domestic homes. J Appl Microbiol. 2001;91:7-21.

4. Cowling BJ, Chan KH, Fang VJ, Cheng CK, Fung RO, Wai W, et al. Facemasks and hand hygiene to prevent influenza transmission in households: a randomized trial. Ann Intern Med. 2009;151:437-46.

5. Centers for Disease Control and Prevention. Novel influenza A (H1N1) virus infections among health-care personnel-United States, April-May 2009. MMWR Morb Mortal Wkly Rep. 2009;58:641-5.

6. Phin NF, Rylands AJ, Allan J, Edwards C, Enstone JE, NguyenVan-Tam JS. Personal protective equipment in an influenza pandemic: a UK simulation exercise. J Hosp Infect. 2009;71:1521.

7. Daugherty EL, Perl TM, Needham DM, Rubinson L, Bilderback A, Rand CS. The use of personal protective equipment for control of influenza among critical care clinicians: a survey study. Crit Care Med. 2009;37:1210-6.

8. Centers for Disease Control and Prevention. Interim pre-pandemic planning guidance: community strategy for pandemic influenza mitigation in the United States-early, targeted, layered use of nonpharmaceutical interventions. Available at: http://www. pandemicflu.gov/plan/community/community_mitigation.pdf. Accessed 30 Aug 2009.

9. Seto WH, Tsang D, Yung RW, Ching TY, Ng TK, Ho M, et al. Effectiveness of precautions against droplets and contact in prevention of nosocomial transmission of severe acute respiratory syndrome (SARS). Lancet. 2003;361:1519-20.

10. Dowell SF, Simmerman JM, Erdman DD, Wu JS, Chaovavanich A, Javadi M, et al. Severe acute respiratory syndrome coronavirus on hospital surfaces. Clin Infect Dis. 2004;39:652-7.

11. Booth TF, Kournikakis B, Bastien N, Ho J, Kobasa D, Stadnyk L, et al. Detection of airborne severe acute respiratory syndrome (SARS) coronavirus and environmental contamination in SARS outbreak units. J Infect Dis. 2005;191:1472-7.

12. Nicas M, Best D. A study quantifying the hand-to-face contact rate and its potential application to predicting respiratory tract infection. J Occup Environ Hyg. 2008;5:347-52.

13. Bean B, Moore BM, Sterner F, Peterson LR, Gerding DN, Balfour HH Jr. Survival of influenza viruses on environmental surfaces. J Infect Dis. 1982;146:47-51.

14. DuPont Medical Fabrics. Advances in medical fabrics technology improve protection for patients and healthcare professionals. Fabric technology helps protect patients and healthcare workers. Advancing world health. DuPont Medical Fabrics, 2003. Available at: http://www2.dupont.com/Medical_Fabrics/en_US/pdf/ AdvancingWorldHealth.pdf. Accessed 30 Aug 2009.

15. Reed LJ, Muench H. A simple method of estimating fifty per cent endpoints. Am J Hyg. 1938;27:493-7. 
16. Mahy BWJ, van Regenmortel M. Encyclopedia of virology. vol. 5, 3rd ed. Amsterdam: Elsevier; 2008.

17. Qian Y, Willeke K, Grinshpun SA, Donnelly J, Coffey CC. Performance of $\mathrm{N} 95$ respirators: filtration efficiency for airborne microbial and inert particles. Am Ind Hyg Assoc J. 1998;59: $128-32$.

18. Possamai MA. SARS and health worker safety: lessons for influenza pandemic planning and response. Healthc Pap. 2007;8:18-28.

19. MacIntyre CR, Cauchemez S, Dwyer DE, Seale H, Cheung P, Browne $\mathrm{G}$, et al. Face mask use and control of respiratory virus transmission in households. Emerg Infect Dis. 2009;15:233-41.

20. Lau JT, Kim JH, Tsui HY, Griffiths S. Anticipated and current preventive behaviors in response to an anticipated human-tohuman H5N1 epidemic in the Hong Kong Chinese general population. BMC Infect Dis. 2007;7:18-29.

21. Harper GJ. Airborne micro-organisms: survival tests with four viruses. J Hyg (Lond). 1961;59:479-86.

22. Lowen AC, Mubareka S, Steel J, Palese P. Influenza virus transmission is dependent on relative humidity and temperature. PLoS Pathog. 2007;3:1470-6.

23. Australian Government Department of Health. Australian Government Department of Health and ageing guidelines for the prevention and control of influenza outbreaks in residential care facilities for public health units in Australia. Australian Government Department of Health, 2005.
24. World Health Organization. World Health Organization infection control recommendations for avian influenza in health-care facilities. (Amended 13 April 2008). Available at: http://www.who. int/csr/disease/avian_influenza/guidelines/aidememoireinfcont/en/ index.html. Accessed 30 Aug 2009.

25. Muto CA, Sistrom MG, Strain BA, Farr BM. Glove leakage rates as a function of latex content and brand: caveat emptor. Arch Surg. 2000;135:982-5.

26. UK Department of Health/UK Health Protection Agency. Pandemic influenza: guidance for infection control in critical care. Department of Health, UK. 2008. Available at: http://www. dh.gov.uk/prod_consum_dh/groups/dh_digitalassets/@dh/@en/ documents/digitalasset/dh_084179.pdf. Accessed 30 Aug 2009.

27. Sehulster L, Chinn RY. Centers for Disease Control and Prevention. Guidelines for environmental infection control in healthcare facilities: recommendations of $\mathrm{CDC}$ and the Healthcare Infection Control Practices Advisory Committee (HICPAC). MMWR Recomm Rep. 2003;52:1-42.

28. Tan NC, Goh LG, Lee SS. Family physicians' experiences, behaviour, and use of personal protection equipment during the SARS outbreak in Singapore: do they fit the Becker Health Belief Model? Asia Pac J Public Health. 2006;18(3):49-56.

29. Thomas Y, Vogel G, Wunderli W, Sute P, Witschi M, Koch D, et al. Survival of influenza virus on banknotes. Appl Environ Microbiol. 2008;74:3002-7. 